\title{
Emotional Characteristics of Adolescents in Monocultural and Multicultural Families in Korea
}

\author{
In-Young Ahn', Jiyeong Seo', Dongyun Lee ${ }^{1}$, So-Jin Lee ${ }^{2}$, Boseok Cha ${ }^{2}$, \\ Cheol-Soon Lee ${ }^{3}$, Bong-Jo Kim², Chul-Soo Park ${ }^{2}$, and Jae-Won Choi ${ }^{4}$ \\ 1 Department of Psychiatry, Gyeongsang National University Changwon Hospital, Changwon, Korea \\ ${ }^{2}$ Department of Psychiatry, Gyeongsang National University School of Medicine, Gyeongsang National University Hospital, Jinju, Korea \\ ${ }^{3}$ Department of Psychiatry, Gyeongsang National University School of Medicine, Gyeongsang National University Changwon Hospital, \\ Changwon, Korea \\ ${ }^{4}$ Division of Child and Adolescent Psychiatry, Department of Psychiatry, Seoul National University Hospital, Seoul, Korea
}

\section{다문화가정 청소년과 한국문화가정 청소년의 정서 특성}

\author{
안인영 ${ }^{1}$, 서지영 ${ }^{1}$, 이동윤 ${ }^{1}$, 이소진 ${ }^{2}$, 차보석 $^{2}$, 이철순 $^{3}$, 김봉조 $^{2}$, 박철수 $^{2}$, 최재원 $^{4}$ \\ 창원경상대학교병원 정신건강의학과, ${ }^{1}$ 경상대학교 의학전문대학원 경상대학교병원 정신건강의학과, ${ }^{2}$ \\ 경상대학교 의학전문대학원 창원경상대학교병원 정신건강의학과, ${ }^{3}$ 서울대학교병원 정신건강의학과 소아청소년분과 ${ }^{4}$
}

\begin{abstract}
Objectives: We aimed to compare the smoking behaviors in adolescents from monocultural and multicultural families and to evaluate the associations between their smoking behavior and number of suicide attempts.

Methods: The data used in this study was collected from The Tenth Korea Youth Risk Behavior Web-based Survey. The differences in the sociodemographic characteristics between the adolescents in the multicultural and monocultural families were analyzed through the $\chi^{2}$-test, and a logistic regression was conducted to evaluate the relationships between the smoking behavior and number of suicide attempts of the adolescents in multicultural families. The process involved an analysis using a complex sample design.

Results: There was significant difference in the weighted rates of the current smoking behavior ( $13.3 \%$ vs. $8.4 \%, \mathrm{p}<0.001)$, experience of violence $(6.8 \%$ vs. $2.3 \%, \mathrm{p}<0.001)$, and number of suicide attempts $(5.4 \%$ vs. $2.7 \%, \mathrm{p}<0.001)$ between the adolescents from the multicultural and monocultural families. In both groups, the current smoking behavior was associated with the number of suicide attempts (multicultural families $\mathrm{OR}=6.5, \mathrm{p}=0.005$; monocultural families $\mathrm{OR}=1.5, \mathrm{p}<0.001$ ).

Conclusion: Our results showed that the percentage of current smokers in the adolescents from multicultural families was higher than that in the monocultural families and that current smoking behavior is related to the number of suicide attempts in both groups, after adjustment for age, sex, socioeconomic status, academic achievement, current smoking behavior, depressive mood and experience of violence.
\end{abstract}

Key Words: Multicultural families; Adolescents; Smoking; Suicidal attempts.

Received: July 27, 2016 / Revision: September 5, 2016 / Accepted: October 13, 2016

Address for correspondence: Jae-Won Choi, Division of Child and Adolescent Psychiatry, Department of Psychiatry, Seoul National University Hospital, 101 Daehak-ro, Jongno-gu, Seoul 03080, Korea

Tel: +82-2-2072-2928, Fax: +82-2-747-2471, E-mail: lingker77@naver.com

서 론

국제결혼과 외국인 노동자들의 증가로 인하여 한국의 다문 화가정의 수는 증가하고 있다. 최근 여성가족부 자료에 따르 면, 다문화가족지원법 개정 이후 다문화가정에 결혼이민자뿐

This is an Open Access article distributed under the terms of the Creative Commons Attribution Non-Commercial License (http://creativecommons.org/licenses/by-nc/3.0) which permits unrestricted non-commercial use, distribution, and reproduction in any medium, provided the original work is properly cited.
만 아니라 외국인 가정까지 포함되면서 다문화가정인구는 2013년 기준 75만 명으로 집계되었고, 매년 증가하여 2020년 에는 100 만 명에 이를 것으로 예상하고 있다.) 다문화가정 수 의 증가에 따라 다문화가정 학생의 수도 증가하고 있는데, 2015년 기준으로 전체 청소년의 수는 2010년 대비 $10.4 \%$ 감 소하였으나 다문화가정 학생의 수는 8만 3천 명으로 전년보 다 $21.7 \%$ 증가하였고 전체 학생수에 대한 다문화가정 학생의 비율도 2010년 $0.4 \%$ 에서 1.4\%로 증가하였다. ${ }^{2)}$ 이 중 초등학생 
의 비중이 $73 \%$ 로 향후 다문화가정의 청소년의 수는 더 빠르 게 증가할 것으로 예상된다.

다문화가정의 청소년들은 단일문화가정의 청소년들이 사춘 기에 겪는 어려움뿐만 아니라 외국인 부모로부터 학습된 문 화와 한국문화 사이의 차이로 인하여 적응의 어려움을 함께 경험하게 된다. ${ }^{3)}$ 유년기에 한국말이 서툰 외국인 아버지 혹은 어머니의 영향으로 아이는 언어발달이 늦어지는데 이는 이후 학습과 대인관계에 영향을 주며, 이로 인하여 스트레스, 우울, 불안증상이 발생할 수 있다. ${ }^{4}$ 초등학교 입학 이후에 외모의 차이는 집단 따돌림의 원인이 될 수 있고 아이가 이러한 차이 를 인지할수록 낮은 학교적응력을 보인다는 보고가 있었다. ${ }^{4)}$ 그리고 부모님의 국적이 서로 다른 경우 아이는 두 문화 사이 에서 어느 쪽의 언어, 가치관, 생활태도를 수용할지 어려워하 고 이로 인하여 부모와의 소통에 어려움을 겪는다.5) 이러한 어려움은 다문화가정의 자녀들에게 단일문화가정의 자녀에 비하여 더 많은 스트레스를 유발할 것으로 생각되며 이러한 스트레스는 청소년기까지 지속되어 한국가정 청소년보다 더 많은 스트레스를 받을 것이다. 이렇게 증가한 청소년기의 스 트레스는 우울, ${ }^{677}$ 자살사고 ${ }^{8)}$ 등을 유발할 뿐만 아니라 흡연, 음주 등과 같은 일탈행동의 위험성을 높인다. ${ }^{9}$

청소년기의 흡연, 음주는 다른 일탈행동에 비하여 경한 일 탈로 여겨지는 경향이 있다. ${ }^{10)}$ 하지만 흡연과 음주보다 더 강한 중독성을 보이는 환각제나 마약 등 약물의 남용과 중독이 시 작되고 ${ }^{11)}$ 어린 시절의 음주, 흡연행동이 성인기의 음주, 흡연으 로 이어지는 위험성을 감안하면 ${ }^{22}$ 이로 인한 사회적 손실은 상 당할 것이다. ${ }^{13)}$ 또한 스트레스, 우울감과의 연관성을 고려할 때 청소년기의 음주와 흡연은 청소년의 정신건강에 큰 영향을 줄 수 있으므로 이에 대한 관심을 기울일 필요가 있다. 이전 연 구에서 음주는 우울증의 위험성을 높이고 ${ }^{14)}$ 흡연은 우울증과 상호작용하는 것으로 보고되었다. ${ }^{15)}$ 우리나라 청소년 1097명 을 대상으로 한 연구에서는 현재 흡연자와 음주자 모두 스트 레스인지율, 우울증상, 자살시도율이 높은 것으로 보고되었 다. ${ }^{10}$ 특히 흡연의 경우 환자-대조군 연구와 전향적 연구에서 모두 자살시도와 연관이 있는 것으로 보고되었다. ${ }^{17)}$

우리나라 청소년의 경우 2006년 이후로 자살이 사망원인 의 1 위를 차지하고 있으며 2014년 기준으로 10만 명당 7.4명이 자살로 사망한다. ${ }^{2}$ 최근 청소년 자살에 대한 관심이 높아지면 서 스트레스를 그 원인으로 지적하고 있는데, 더 많은 스트레 스 요인을 가진 다문화가정 청소년의 경우 자살사고나 시도에 더 취약할 수 있다. 다문화가정 청소년의 경우 한국문화가정 청소년에 비하여 자살시도율과 강도가 더 높고 아버지를 외국 인으로 둔 청소년일수록 더 강도가 높았다. ${ }^{18)}$ 다문화가정 청 소년의 자살로 인한 실제 사망률에 대한 자료는 없지만 이전
연구를 감안할 때 자살로 인한 사망에 더 취약하다고 여겨지 며 이에 대한 관심과 대처가 필요하다.

다문화가정의 청소년을 대상으로 한 흡연율과 음주율 등을 알아보는 역학연구는 있었지만 $\left.{ }^{19}\right)$ 흡연, 음주와 우울감, 자살 등의 정신건강과의 관련성에 대한 연구결과는 아직 제한적이 다. 한국문화가정의 청소년에 비하여 문화적인 측면과 가족관 계, 또래관계 등에서 더 많은 스트레스 요인을 가지고 있기 때 문에 한국문화가정의 청소년과 차이가 있을 것으로 생각된다. 따라서 본 연구에서는 한국문화가정과 다문화가정의 청소년 의 흡연, 음주행위를 비교하고 우울감 및 자살시도와의 연관 성을 확인하고자 한다.

\section{방 법}

\section{대 상}

본 연구의 자료들은 2005년부터 교육부, 보건복지부, 질병 관리본부에서 매년 시행하는 청소년건강행태온라인조사(The Tenth Korea Youth Risk Behavior Web-based Survey) 중 2014년에 시행한 10차 조사의 결과를 사용하였다. 중학교 1학 년부터 고등학교 3학년까지 청소년을 대상으로 시행하였고, 총 799개교의 72060명이 응답하였다. 표본오차를 최소화하 기 위하여 모집단 층화, 표본배분, 표본추출의 단계를 통하여 표본을 추출하였다. 다문화가정은 아버지 혹은 어머니가 태어 난 곳이 한국인지에 대한 질문에 '아니요라고 대답한 청소년 을 대상으로 하였고 부모 모두 한국에서 태어난 경우 한국가 정 청소년으로 분류하였다. 두 부모가 모두 외국인인 외국인 가정의 청소년도 2012년에 교육인적자원부에서 발표한 '다문 화학생 교육선진화 방안'의 다문화가정의 구분에 따라 다문 화가정 청소년에 포함하였다. 하지만 북한 출신의 부모를 둔 청소년의 경우 탈북과정의 외상경험 여부가 확인되지 않았고 언어의 이질성이 다른 국가 출신의 부모와 다르므로 다문화 가정군과 한국문화가정군 모두에서 제외하였다. 본 연구는 질 병관리본부 기관생명윤리위원회(Institutional Review Board, IRB)의 심의를 받은 정부승인통계조사의 결과를 공식적으로 자료 요청하여 학술연구용으로 승인받은 후 사용하였으며, 연 구수행과 관련하여 기관 IRB의 심사면제 승인(IRB No. GNUH 2016-10-003)을 받았다.

\section{평가 항목}

\section{사회인구학적 정보}

나이와 성별, 학교의 종류, 도시규모, 학업성취도, 사회경제 적 수준이 사회인구학적 정보로 조사되었다. 학교의 종류는 중 
학교, 일반계고, 특성화계고로 분류되었고 도시규모는 대도시, 중소도시, 군지역으로 분류되었다. 학업성취도와 사회경제적 수준은 상, 중상, 중, 중하, 하의 총 5 단계로 나누어 조사되었다.

\section{음주와 흡연행위}

음주행위는 평생 음주 경험률과 현재 음주율을 조사하였 다. 평생 음주 경험률은 평생 동안 1잔 이상 술을 마셔 본 적 이 있는 사람의 분율이고 현재 음주율은 최근 30 일 동안 1 잔 이상 술을 마신 적이 있는 사람의 분율이었다. 흡연행위도 평 생 흡연 경험률과 현재 흡연율을 조사하였다. 평생 흡연 경험 률은 평생 동안 담배를 한두 모금이라도 피운 경험이 있는 사 람의 분율이고 현재 흡연율은 최근 30 일 동안 1 일 이상 흡연 한 사람의 분율이었다.

\section{우울감과 자살사고, 자살시도, 폭력경험 여부}

우울감 경험률은 최근 12 개월 동안 2주 내내 일상생활을 중 단할 정도로 슬프거나 절망감을 느낀 적이 있는 사람의 분율 을 확인하였고 자살생각률은 최근 12 개월 동안 심각하게 자 살을 생각한 적이 있는 사람의 분율, 자살시도율은 최근 12 개 월 동안 자살을 시도한 적이 있는 사람의 분율이었다. 우울감 경험과 자살사고, 자살시도의 반복 여부는 조사되지 않았다. 폭력경험률은 '최근 12 개월 동안 친구, 선배, 성인에게 폭력(신 체적 폭행, 협박, 따돌림 등)을 당해 병원에서 치료를 받은 적 이 있습니까?라는 질문에 ‘0번', '1번', '2번', ‘3번', ‘번', ‘5번' ‘6 번 이상' 중 하나를 선택하게 하고 1번 이상 경험이 있는 사람 의 수를 모두 더하여 분율을 구하였다.

\section{통계분석 방법}

청소년건강행태온라인조사는 복합표본설계를 하였으므로 정확한 통계분석을 위하여 층화변수, 집락변수, 가중치변수를 지정하여 복합표본분석을 시행하였다. 다문화 청소년 그룹과 한국문화 청소년 그룹 간의 특성을 비교하기 위하여 카이스 퀘어 검증(chi-square test)을 시행하였다. 다문화가정군과 한 국문화가정군의 현재 흡연행위와 자살시도의 위험성을 높이 는 인자를 확인하기 위하여 로지스틱 회귀분석(logistic regression analysis)을 시행하였다. 현재 흡연율을 종속변인으로 지 정하고 현재 음주율과 우울감 경험률, 이전 폭력의 경험률을 독립변인으로 지정하여 현재 흡연행위의 위험요인을 확인하 였다. 자살시도의 위험요인을 확인하기 위하여 자살시도를 종 속변수로 지정하고 현재 흡연율과 현재 음주율, 우울감 경험 률, 이전 폭력의 경험률을 독립변인으로 지정하였다. 두 분석 모두 두 군의 특성 중 유의하게 차이가 있었던 성별, 나이, 학 업성취도, 사회경제적 수준과 회귀분석에서 현재 흡연행위와
자살시도와 연관성이 있었던 독립변수들을 보정하였다. 모든 통계분석은 PASW Statistics version 22.0(SPSS Inc., Chicago, $\mathrm{IL}, \mathrm{USA}$ )을 사용하였고 통계적 유의성 판단의 기준은 양측 검정 $\mathrm{p}$ 값 0.05 미만으로 설정하였다.

\section{결 과}

\section{두 군 간의 사회인구학적 특성의 비교}

연구대상자는 미해당과 결측치를 제외한 66919명이었고 이 중 다문화가정의 청소년은 617명이었고 남학생은 300명(50.3\%) 이었다. 다문화가정 청소년의 평균나이는 14.7 세로 한국문화 가정의 청소년(15.0세)보다 낮았고 $(\mathrm{p}<0.001)$, 다문화가정에서 중 학생의 비중이 상대적으로 높았다 $(56.7 \%$ vs. $48.7 \%, \mathrm{p}<0.001)$. 사회경제적 수준은 한국문화가정이 다문화가정에 비하여 중 상의 비율이 상대적으로 높았다(15.1\% vs. $26.9 \%, \mathrm{p}<0.001)$. 학 업성취도도 한국문화가정의 청소년이 다문화가정의 청소년에 비하여 상과 중상의 비율이 높았다 $(9.3 \%$ vs. $12.3 \%, 19.1 \%$ vs. $25.4 \%, \mathrm{p}<0.001)$. 우울감 경험률과 자살생각률은 두 군 간에 통계적으로 유의한 차이는 없었지만 자살시도율는 다문화가 정의 청소년에서 $5.4 \%$ 로 한국문화가정의 $2.7 \%$ 에 비하여 두 배 가량 높았다 $(\mathrm{p}<0.001)$. 폭력경험률 또한 다문화가정의 청소년 이 $6.8 \%$ 로 한국문화가정의 청소년(2.3\%)에 비하여 통계적으 로 유의하게 높은 결과를 보였다 $(\mathrm{p}<0.001)$ (Table 1).

\section{두 군 간의 음주율, 흡연율 비교}

평생 음주 경험률은 한국문화가정의 청소년(42.2\%)이 다문 화가정의 청소년(37.7\%)에 비하여 높았지만 통계적으로 유의 하지 않았다 $(\mathrm{p}=0.057)$. 현재 음주율은 다문화가정의 청소년 (17.1\%)이 한국문화가정의 청소년(16.1\%)보다 높았으나 통계적 으로 유의한 차이는 아니었다( $\mathrm{p}=0.535)$. 평생 흡연 경험률은 다문화가정의 청소년(23.6\%)이 한국문화가정의 청소년(19.0\%) 보다 높았으며 $(\mathrm{p}=0.012)$, 현재 흡연율도 다문화가정의 청소년 이 더 높았다(13.3\% vs. 8.4\%, $\mathrm{p}<0.001$ )(Table 2).

\section{현재 흡연행위와 자살시도와의 연관성}

다문화가정과 한국문화가정의 청소년 모두 현재 음주행위 [다문화가정군, odds $\operatorname{ratio}(\mathrm{OR})=33.2, \mathrm{p}<0.001$; 한국문화가정 군, $\mathrm{OR}=10.0, \mathrm{p}<0.001]$ 와 우울감(다문화가정군, $\mathrm{OR}=2.0, \mathrm{p}=$ 0.042 ; 한국문화가정군, $\mathrm{OR}=1.6, \mathrm{p}<0.001)$, 이전 폭력의 경험 (다문화가정군, $\mathrm{OR}=3.2, \mathrm{p}=0.040$; 한국문화가정군, $\mathrm{OR}=2.3$, $\mathrm{p}<0.001)$ 이 현재 흡연행위와 연관성이 있는 것으로 확인되었 다. 회귀분석 시 각 독립변수의 영향을 고려하여 인구학적 특 성 외에 현재 음주행위, 우울감, 이전 폭력의 경험 모두를 보 
정하였다.

자살시도와의 연관성은 이전 회귀분석에서 현재 흡연행위 가 우울감과 현재 음주행위, 이전 폭력의 경험과 연관이 있었 기 때문에 인구학적 특성과 함께 모든 독립변수를 보정하였 다. 한국문화가정의 청소년에서 우울증상 $(\mathrm{OR}=10.1, \mathrm{p}<0.001)$, 이전 폭력의 경험 $(\mathrm{OR}=4.5, \mathrm{p}<0.001)$, 현재 음주행위 $(\mathrm{OR}=2.1$, $\mathrm{p}<0.001)$, 현재 흡연행위 $(\mathrm{OR}=1.5, \mathrm{p}<0.001)$ 의 순서로 자살시 도와의 연관성이 확인되었다. 다문화가정의 경우 우울감 $(\mathrm{OR}=17.2, \mathrm{p}<0.001)$ 과 현재 흡연행위 $(\mathrm{OR}=6.5, \mathrm{p}=0.005)$ 가 자 살시도와 연관성을 가지는 것으로 확인되었다(Table 3).

\section{고 찰}

본 연구에서는 다문화가정 청소년들과 한국문화가정 청소 년들의 음주와 흡연 실태를 파악하고, 현재 흡연행위와 자살 시도와의 연관성에 대하여 알아보았다. 현재 음주율은 두 군 간에 유의한 차이는 없었지만 현재 흡연율은 다문화가정의 청소년이 유의하게 높았다. 두 군 간에 우울감과 자살계획은 유의한 차이가 없었지만 자살시도와 폭력의 경험은 다문화가 정 청소년에서 높았다. 한국문화가정군과 다문화가정군에서 서로 연관성을 보였던 우울감과 현재 흡연행위를 보정한 후에 도 우울감과 현재 흡연행위는 한국문화가정군과 다문화가정

Table 1. General characteristics of multicultural and monocultural adolescents

\begin{tabular}{|c|c|c|c|}
\hline Variables & Multicultural $(n=617)$ & Monocultural $(n=66302)$ & $\mathrm{p}$ \\
\hline Male, n (weighted \%) & $300(50.3)$ & $33403(52.0)$ & 0.444 \\
\hline Age (years), weighted mean (SD) & $14.7(0.08)$ & $15.0(0.02)$ & $<0.001$ \\
\hline School, n (weighted \%) & & & $<0.001$ \\
\hline Middle school & $373(56.7)$ & $33429(48.7)$ & \\
\hline Academic high school & $189(31.7)$ & $27761(43.0)$ & \\
\hline Vocational high school & $55(11.5)$ & $5112(8.3)$ & \\
\hline Living area, n (weighted \%) & & & $<0.001$ \\
\hline Metropolis & $306(46.6)$ & $28447(43.8)$ & \\
\hline Cities & $241(44.1)$ & $34775(52.4)$ & \\
\hline Rural & $70(9.3)$ & $3080(3.7)$ & \\
\hline Self-rated academic achievement, n (weighted \%) & & & $<0.001$ \\
\hline Very high & $60(9.3)$ & $8256(12.3)$ & \\
\hline High & $122(19.1)$ & $16844(25.4)$ & \\
\hline Middle & $172(29.0)$ & $18798(28.4)$ & \\
\hline Low & $181(29.7)$ & $15693(23.8)$ & \\
\hline Very low & $82(12.8)$ & $6711(10.2)$ & \\
\hline Social economic status, n (weighted \%) & & & $<0.001$ \\
\hline Very high & $39(7.2)$ & $5213(8.0)$ & \\
\hline High & $93(15.1)$ & $17658(26.9)$ & \\
\hline Middle & $304(49.0)$ & $32624(48.9)$ & \\
\hline Low & $143(21.8)$ & $8857(13.3)$ & \\
\hline Very low & $38(7.0)$ & $1950(3.0)$ & \\
\hline Depressive mood, n (weighted \%) & $166(26.9)$ & $17304(26.2)$ & 0.700 \\
\hline Suicidal ideation, n (weighted \%) & $77(13.6)$ & $8422(12.7)$ & 0.547 \\
\hline Suicidal attempt, n (weighted \%) & $30(5.4)$ & $1781(2.7)$ & $<0.001$ \\
\hline Experience of violence, $\mathrm{n}$ (weighted \%) & $40(6.8)$ & $1483(2.3)$ & $<0.001$ \\
\hline
\end{tabular}

SD: standard deviation

Table 2. Comparison of drinking and smoking behaviors between multicultural and monocultural adolescents

\begin{tabular}{lrrr}
\hline & Multicultural & Monocultural & $\mathrm{p}$ \\
\hline Experience of drinking, $\mathrm{n}$ (weighted \%) & $216(37.7)$ & $27680(42.2)$ & 0.057 \\
Current drinking behaviors, $\mathrm{n}$ (weighted \%) & $95(17.1)$ & $10266(16.1)$ & 0.535 \\
Experience of smoking, $\mathrm{n}$ (weighted \%) & $129(23.6)$ & $12229(19.0)$ & 0.012 \\
Current smoking behaviors, $\mathrm{n}$ (weighted \%) & $71(13.3)$ & $5322(8.4)$ & $<0.001$ \\
\hline
\end{tabular}


Table 3. Associated risk factors for current smoking behavior and suicidal attempts using logistic regression in multicultural and monocultural adolescents

\begin{tabular}{|c|c|c|c|c|}
\hline \multirow{2}{*}{ Risk factors, OR $(95 \% \mathrm{Cl})$} & \multicolumn{2}{|c|}{ Current smoking behaviors ${ }^{\ddagger}$} & \multicolumn{2}{|c|}{ Suicidal attempts ${ }^{\S}$} \\
\hline & Multicultural & Monocultural & Multicultural & Monocultural \\
\hline \multicolumn{5}{|l|}{ Current smoking behaviors } \\
\hline No & - & - & 1 [Reference] & 1 [Reference] \\
\hline Yes & - & - & $6.5(1.7-24.4)^{*}$ & $1.5(1.3-1.8)^{\dagger}$ \\
\hline \multicolumn{5}{|l|}{ Current drinking behaviors } \\
\hline No & 1 [Reference] & 1 [Reference] & 1 [Reference] & 1 [Reference] \\
\hline Yes & $33.2(17.0-65.0)^{\dagger}$ & $10.0(9.2-10.7)^{\dagger}$ & $1.4(0.4-4.6)$ & $2.1(1.8-2.5)^{\dagger}$ \\
\hline \multicolumn{5}{|l|}{ Depressive mood } \\
\hline No & 1 [Reference] & 1 [Reference] & 1 [Reference] & 1 Reference] \\
\hline Yes & $2.0(1.0-4.1)^{*}$ & $1.6(1.5-1.7)^{\dagger}$ & $17.2(6.0-49.0)^{\dagger}$ & $10.1(8.8-11.5)^{\dagger}$ \\
\hline \multicolumn{5}{|l|}{ Experience of violence } \\
\hline No & 1 [Reference] & 1 [Reference] & 1 [Reference] & 1 [Reference] \\
\hline Yes & $3.2(1.1-9.6) *$ & $2.3(1.9-2.8)^{\dagger}$ & $3.3(0.8-13.0)$ & $4.5(3.7-5.4)^{\dagger}$ \\
\hline
\end{tabular}

${ }^{*} p<0.05,{ }^{\dagger} p<0.001,{ }^{\ddagger}$ adjusted by sex, age, school performance, social economic status, current drinking behaviors, depressive mood, experience of violence, ${ }^{\S}$ adjusted by sex, age, school performance, social economic status, current drinking behaviors, current smoking behaviors, depressive mood, experience of violence. Cl: confidence interval, OR: odds ratio

군 모두에서 자살시도와 유의한 연관성을 보였다.

청소년 시기의 우울감은 호르몬의 변화 등의 생물학적인 영 향과 가족력 등의 유전학적 영향, 그리고 급성 혹은 만성 스 트레스인 심리사회적인 영향이 복합적으로 작용하고 우울감 에 의하여 학교거부와 비행행동, 중독행위, 자살사고와 시도 등의 외현화 문제가 발생한다. ${ }^{6)}$ 본 연구에서도 우울감은 한국 문화가정군과 다문화가정군 모두에서 흡연행위, 자살시도와 연관성을 보였다. 게다가 상대적으로 연구결과가 부족한 다문 화가정 청소년에서도 우울감이 흡연행위, 자살시도와 연관성 이 있음을 확인한 것은 이전의 연구결과들을 보충함과 동시 에 지지하는 의미가 있다.

청소년의 흡연과 관련된 요인으로 우울증에 대한 연구결과 는 비교적 많은 편이다. 청소년을 대상으로 한 전향적 코호트 연구에서는 우울증이 있는 청소년이 흡연의 시작이 빠르고 우울증의 점수가 높을 수록 더 빈번하게 흡연을 하였다. ${ }^{20)}$ 본 연구에서도 우울감은 흡연의 위험을 다문화가정 청소년에서 는 2 배, 한국문화가정 청소년에서는 1.6 배 높이는 것으로 확 인되어 이전의 연구결과를 뒷받침한다. 하지만 반대로 흡연이 우울감을 유발할 수 있다는 연구결과 ${ }^{21)}$ 도 있는데 흡연 청소 년에서 우울감의 발생 위험이 2 배 이상 증가하였고 이는 니코 틴이 중추신경계에 영향을 주어 우울감이 나타날 수 있는 가 능성을 보고하였다. 각기 다른 방향성을 보고한 15 개의 종단 적 연구를 분석한 리뷰연구에서는 우울증과 흡연이 상호작용 하는 것으로 보고하였다. ${ }^{15)}$ 따라서 두 변수 간의 연관성에 대 하여는 우울감으로 인하여 흡연행동이 증가함과 동시에 흡연 으로 인한 니코틴의 영향이 우울감을 악화시키는 상호작용 을 모두 고려해야 할 것이다.
본 연구에서는 두 군 모두 현재 흡연행위가 자살시도의 위 험성과 연관이 있는 것으로 확인되었다. 정신과질환을 가지는 347 명을 대상으로 한 연구에서 흡연이 자살행동의 위험을 2.6 배 높이는 것으로 보고되었고 이에는 뇌척수액의 세로토닌 농도와 흡연량이 음의 관계를 보이는 것으로 낮은 세로토닌 농도가 자살시도에 영향을 줄 것으로 주장하였다. ${ }^{22)}$ 정상대조 군과 정신과질환 환자들을 비교한 연구에서도 정신과질환을 보정했음에도 남자 환자의 경우 흡연이 자살시도 위험성을 2.6 배 높였다. ${ }^{23)}$ 자살사망과 흡연과의 연관성에 대한 메타연구 에서는 이전 흡연의 경험이 위험을 1.28 배 높였고, 현재 흡연은 1.8 배 위험을 높였으며 위험성은 흡연량과 비례하였다. ${ }^{24)}$ 동물 모델에서 만성적으로 니코틴에 노출이 되었을 경우 세로토닌 의 농도가 감소하는 것다과 흡연자의 뇌척수액의 세로토닌의 농도가 감소되어 있는 소견 ${ }^{22)}$ 은 니코틴에 의한 세로토닌의 농 도 감소가 자살시도와 연관이 있음을 시사한다. 하지만 본 연 구에서 흡연의 경우 지난 한 달간 흡연의 경험이 있을 경우 현 재 흡연행위로 정의하였지만 이전 연구에서는 만성적인 흡연 으로 인한 니코틴의 영향을 확인하였다. 본 연구의 현재 흡연 행위는 그 정도가 다양하여 해석에 주의가 필요하며 이를 확 인하기 위하여 정량적인 측정에 의한 체내 니코틴농도와 우 울감, 자살시도와의 연관성에 대한 연구가 필요하다.

이전 폭력의 경험은 두 군 모두에서 현재 흡연행위와 유의 한 연관성을 보였다. 그리고 자살시도와 이전 폭력의 경험의 관계는 한국문화가정군은 유의한 연관성이 확인되었고 다문 화가정군에서도 비교적 의미 있는 연관성을 보였다 $(\mathrm{p}=0.088)$. 설문 시 질문이 '친구, 선배, 성인에게 폭력을 당하여 병원에서 치료받은 경험'으로 또래관계에서의 폭력인지 가정 내 폭력인 
지의 구분은 어렵다. 하지만 이전 연구에서 학대와 부정적인 경험이 흡연의 위험을 높이는 보고가 있었고ํ) 이러한 경험이 스트레스로 작용하여 우울감과 자살시도에도 영향을 줄 것 으로 여겨진다. 특히 다문화가정 청소년들의 경우 한국문화가 정군에 비하여 사회적 지지기반과 부모의 지지체계가 부족한 것을 감안할 때 폭력, 학대 등의 부정적 경험에 노출될 위험 이 높을 것으로 예상되지만 아직 이에 대한 연구는 부족하고 대처방안도 미미한 실정이다.

이번 연구결과에서 다문화가정의 청소년들이 한국문화가 정의 청소년에 비하여 사회경제적인 상태와 학업성취도가 낮 음이 확인되었다. 다문화가정 청소년에 대한 다른 연구에서도 부모의 낮은 사회경제적 지위와 학습 부진이 보고되었고 ${ }^{26)}$ 그 로 인한 자아존중감의 혼란 등으로 우울, 불안 등의 증상들 이 증가함이 보고되었다. ${ }^{27)}$ 이러한 스트레스와 우울증상들은 흡연과 음주의 위험인자로 알려져 있다. ${ }^{14,15)}$ 하지만 이번 연구 에서 현재 음주율은 다문화가정의 청소년들과 한국문화가정 의 청소년 간에 통계적인 차이가 없었지만 현재 흡연율은 통 계적으로 유의하게 다문화가정의 청소년에서 더 높은 것으로 확인되었다. 이러한 차이가 나는 것은 다문화가정 청소년의 특징적인 또래관계가 영향을 줄 가능성이 있다. 이전 연구에 서는 흡연과 음주 모두에서 또래관계가 중요한 동기요인이지 만 ${ }^{28)}$ 또래관계의 질·양과 음주, 흡연과의 연관성에 대하여는 보고된 바가 없다. 음주는 혼자 하기보다는 다른 사람들과 함 께 하는 경우가 많은 반면 ${ }^{29}$ 흡연의 경우 혼자 하는 경우가 음 주보다 많을 것으로 생각된다. 외모, 언어 등의 이유로 ${ }^{4}$ 또래 관계에 어려움이 예상되는 다문화가정의 경우 상대적으로 혼 자 할 수 있는 중독행동의 비율이 높을 수 있다. 따라서 향후 연구에서는 흡연과 음주 행동의 차이를 구별하고 또래관계와 의 연관성에 대한 연구가 필요하다.

이번 연구를 통하여 다문화가정 청소년들과 한국문화 청소 년들 모두에서 우울감뿐만 아니라 현재 흡연율이 자살시도율 과 연관성이 있으며 자살시도의 위험과 연관성이 있는 현재흡 연행위가 상대적으로 다문화가정군에서 더 높은 것을 확인한 것에 의미가 있겠다. 그리고 흡연과 음주를 중독과 연관된 일 탈행동으로 함께 생각했지만 이번 연구를 통하여 두 행동의 차 이가 있을 수 있으며 이에 대한 연구의 필요성을 제기하였다.

하지만 몇 가지 제한점이 있는데 먼저 자료수집의 과정에서 정신과적 진단에 대한 고려가 없이 일반 인구와 정신과 환자 군이 함께 다문화가정군과 한국문화가정군으로 분류되어 분 석되었다. 우울감과 관련하여 최근 우울감의 여부를 '예' 혹은 '아니오'로만 확인하였기에 일시적인 우울감인지, 주요우울장 애에 속하는 질환의 수준인지, 반복적 삽화인지 구분이 어렵 다. 그리고 설문 기간이 4월 중에 실시되어 신학기 적응으로
인한 어려움이 반영되었는지 확신할 수 없다는 점이다. 중학 교 1학년 혹은 고등학교 1학년의 경우 상급학교로 진학 이후 변화에 대한 적응이 완전하지 않는 상태로 설문에 응했을 가 능성이 있으므로 결과해석에 주의가 필요할 것이다.

\section{결 론}

본 연구에서는 다문화가정과 한국문화가정의 청소년의 음 주 및 흡연 실태를 파악할 수 있었고, 한국문화가정 청소년에 비하여 다문화가정 청소년에서 현재 흡연행위가 더 높은 비 율로 나타남을 확인하였다. 두 군 모두 이전에 알려진 우울감 과 더불어 현재 흡연행위가 자살시도와 연관성이 있음을 확 인하였다. 이번 연구결과는 흡연행위가 여러 비행행동 중의 하 나로만 여겨지는 것이 아니라 자살시도의 위험을 높일 수 있 는 행위로써 관심을 가질 필요가 있음을 강조하고 있다. 그리 고 현재 흡연율이 높았던 다문화가정 청소년에서 흡연행위 여 부에 대해 더 관심을 가질 필요가 있으며 흡연율을 낮추기 위 한 금연 교육 등의 프로그램을 적극적으로 고려해야 할 것이 다. 그리고 향후 연구에서는 청소년의 중독관련행동 중 음주 행동과 흡연행동의 차이를 파악하는 것이 청소년 정신건강 및 중독증상에 대한 다각적인 접근에 중요한 전략이 될 것이다.

중심 단어: 다문화가정; 청소년; 흡연; 자살시도.

\section{Conflicts of Interest}

The authors have no financial conflicts of interest.

\section{REFERENCES}

1) Ministry of Gender Equality and Family. Statistics of multicultural families in Korea. Seoul: Ministry of Gender Equality and Family; 2014.

2) Statistics Korea. Statistics of adolescents in Korea. Daejeon: Statistics Korea;2016.

3) Oh HS. A study on life satisfaction among adolescents of multicultural families in the area of ChungnamDo: focus on acculturative stress and social support. Asan: Hoseo University;2010.

4) Seol DH, Kim YT, Kim HM, Yoon, HS, Lee HK, Yim KT, et al. Foreign Wives' Life in Korea: Focusing on the Policy of Welfare and Health. Seoul: Ministry of Health and Welfare;2005.

5) Jung HS. Multicultural Youth. Seoul: Books I\&I;2010. p.58-59.

6) Thapar A, Collishaw S, Pine DS, Thapar AK. Depression in adolescence. Lancet 2012;379:1056-1067.

7) Woo CY, Park AC, Jeong HH. The structural relationship among human relations, stress, depression and suicidal ideation of adolescents by genders and level of school. Korean J Educ Psychol 2010; 24:19-38.

8) Kim HS. Verification of the relationship between adolescents stress, self efficacy, depression and suicidal ideation. Stud Korean Youth 2009;20:203-225.

9) Simantov E, Schoen C, Klein JD. Health-compromising behaviors: why do adolescents smoke or drink?: identifying underlying risk and protective factors. Arch Pediatr Adolesc Med 2000;154:10251033. 
10) Hwang SH. A study of social bonding, self-control, and social learning theories on the drinking and smoking behaviors of adolescent. Stud Korean Youth 2009;20:113-139.

11) Lee GC, Kim YJ, Shin YK, Eun BL, Park SH, Tockgo YC. The state of smoking and alcohol usein Korean adolescent. Korean J Pediatr 1997;40:307-317.

12) Hemmingsson T, Kriebel D. Smoking at age 18-20 and suicide during 26 years of follow-up-how can the association be explained? Int J Epidemiol 2003;32:1000-1004.

13) Park NH. Gender differences in the association between psychosocial factors and smoking, drinking in adolescents. Korean J Health Educ Promot 2005;22:123-136.

14) Boden JM, Fergusson DM. Alcohol and depression. Addiction 2011; 106:906-914.

15) Chaiton MO, Cohen JE, O’Loughlin J, Rehm J. A systematic review of longitudinal studies on the association between depression and smoking in adolescents. BMC Public Health 2009;9:356.

16) Kim HO, Jeon MS. The relationship between smoking, drinking and the mental health in adolescents. J Korean Public Health Nurs 2007;21:217-229.

17) Hughes JR. Smoking and suicide: a brief overview. Drug Alcohol Depend 2008;98:169-178.

18) Kim HS, Kim DS. Adolescents of multi-cultural families and differential risks of suicidal behaviors. Korean J Sociol 2014;48:3566.

19) Ko SD. Correlate of the smoking and drinking behavior among adolescents from multi-cultural families. J Korean Alcohol Sci 2015; 16:99-108.

20) Escobedo LG, Reddy M, Giovino GA. The relationship between de- pressive symptoms and cigarette smoking in US adolescents. Addiction 1998;93:433-440.

21) Goodman E, Capitman J. Depressive symptoms and cigarette smoking among teens. Pediatrics 2000;106:748-755.

22) Malone KM, Waternaux C, Haas GL, Cooper TB, Li S, Mann JJ. Cigarette smoking, suicidal behavior, and serotonin function in major psychiatric disorders. Am J Psychiatry 2003;160:773-779.

23) Schneider B, Schnabel A, Weber B, Frölich L, Maurer K, Wetterling T. Nicotine use in suicides: a case-control study. Eur Psychiatry 2005;20:129-136.

24) Li D, Yang X, Ge Z, Hao Y, Wang Q, Liu F, et al. Cigarette smoking and risk of completed suicide: a meta-analysis of prospective cohort studies. J Psychiatr Res 2012;46:1257-1266.

25) Olausson P, Engel JA, Söderpalm B. Involvement of serotonin in nicotine dependence: processes relevant to positive and negative regulation of drug intake. Pharmacol Biochem Behav 2002;71:757771.

26) Yoo BN, Park KO, Choi JY. Association between self-esteem and health behavior of the children with multi-cultural family background. J Korean Soc Sch Health Educ 2010;11:41-55.

27) Nam YJ, Lee S. A comparative study on the mother's attachment, self-concept, daily stress, depression of children from multicultural and typical Korean families. Korean J Community Living Sci 2009; 20:357-367.

28) Hwang SH. Parental and peer factors influence on adolescents' drinking and smoking behaviors. J Korean Assoc Health Med Sociol 2010;27:81-103.

29) Jung EH. Juvenile Drinking and Dietary Habit in High School Students. Korean J Community Nutr 2004;9:29-37. 